\title{
The AATS Academy: Development of a unique concept in medical education
}

\author{
V. Sreenath Reddy, MD, MBA, FACS, ${ }^{\mathrm{a}}$ John S. Ikonomidis, MD, PhD, ${ }^{\mathrm{b}}$ and Fred A. Crawford, Jr, MD ${ }^{\mathrm{b}}$
}

At its December 2007 meeting, the Council of The American Association for Thoracic Surgery (AATS) voted to develop an AATS Academy for aspiring division chiefs as a part of its mission of "promoting scholarship in thoracic and cardiovascular surgery." This measure was taken in recognition of the lack of any formal educational process to prepare individuals for the administrative role of a division chief. A committee was appointed, consisting of Bartley Griffith, Irving Kron, Thoralf Sundt, and Fred Crawford as chairman. After a series of conference calls and faceto-face meetings, a tentative program was developed. Letters were sent to current division chiefs and department chairs requesting nominations of individuals who should be considered as participants in this program. Forty-five cardiothoracic surgeons were nominated, and ultimately 19 were selected. Candidates were selected on the basis of accomplishments documented in their curricula vitae, letters of recommendation, and personal knowledge by the Academy committee. Faculty members were selected on the basis of expertise in particular areas, experience as a division chief or department chair, and service in national organizations and on various regulatory bodies, such as the American Board of Thoracic Surgery and the Thoracic Surgery Residency Review Committee. A secondary but important goal of the Academy was to promote extensive interaction between faculty members and participants so that personal relationships could be developed to foster future mentoring. To that end, the faculty member to student ratio was approximately $1: 1$, and the faculty members were required to agree that they would be present for all aspects of the entire program. In other words, brief guest appearances to give a talk and leave were strongly discouraged. The meeting room was set up in an informal classroom style, with assigned seating so that 2 faculty members and 2 participants were at each table, again to promote interaction.

The initial Academy took place just before the 2009 AATS meeting in Boston and began with a brief introduc-

\footnotetext{
From the Division of Cardiothoracic Surgery, ${ }^{\mathrm{a}}$ University of Texas Health Science Center, San Antonio, Tex; and the Division of Cardiothoracic Surgery, ${ }^{\mathrm{b}}$ Medical University of South Carolina, Charleston, SC

Disclosures: Authors have nothing to disclose with regard to commercial support.

Received for publication Jan 5, 2011; revisions received Jan 5, 2011; accepted for publication Jan 20, 2011.

Address for reprints: Fred A. Crawford, Jr, MD, Distinguished University Professor, Division of Cardiothoracic Surgery, Medical University of South Carolina, 25 Courtenay Dr, Suite 7018, Charleston, SC 29425 (E-mail: crawfrdf@musc.edu). J Thorac Cardiovasc Surg 2011;141:1101-2

$0022-5223 / \$ 36.00$

Copyright (C) 2011 by The American Association for Thoracic Surgery doi:10.1016/j.jtcvs.2011.01.037
}

tory program, followed by a reception and dinner with faculty members and participants. The program began the next day at 7:00 AM and continued until 5:30 PM (program available online at http://www.ctsnet.org/announcements/ announcement $817 . \mathrm{html}$ ). This was followed by a reception for faculty members, participants, and guests. In addition to the formal presentations, ample time was allowed for discussion, including both panels and discussions from the floor by both participants and faculty members. Feedback from participants, both formal and informal, was promoted and was extensive. It was quickly apparent that the faculty members in some cases were learning as much as the participants, with many expressing their regrets that such a program had not been available to them. Feedback also suggested that some of the topics should be covered more extensively in a subsequent session (which occurred at the 2010 AATS meeting). A few topics were subsequently judged to be somewhat less important, and these were dropped, with replacements added for the second Academy, which was held in Toronto in April 2010.

From the viewpoint of 2 attendees (V.S.R. and J.S.I.), the AATS Academy is serving as a concrete testament to the mandate of the AATS to develop future leaders in the field of cardiothoracic surgery. A significant number of individuals with national and international reputations set aside 2 days of their time to participate as faculty members, and this level of commitment resulted in a very high quality program. This afforded the optimal opportunity for dissemination of very well organized and presented information, and also for outstanding networking and conversation opportunities between this distinguished faculty and the attendees.

The messages conveyed by the speakers of the Academy were focused and succinct, and they covered the spectrum of the appropriate issues that emerging leaders in the field would encounter. One of us (J.S.I.) was fortunate to attend this first Academy and summarizes here the most important things learned from the Academy, all of which are used in navigating through the transition to the role of a new division chief:

1. The primary purpose of the cardiothoracic surgical division chief is to mentor and promote the careers of his or her faculty.

2. The academic cardiothoracic division chief must be well versed in clinical and basic science research, be aware of current funding availability and application strategies, and have sufficient experience to mentor young faculty members as they navigate this difficult path. 
3. A leader determines the goals and inspires and guides other to accomplish them.

4. The manner in which a job is structured during the negotiation process has a profound impact on subsequent success in that position.

5. Preparation and enthusiasm are the keys to successful job competition and negotiation.

6. Preparation and careful strategy will determine one's success in interpersonal negotiations, the ultimate goal of which should be in a win-win agreement.

7. One of the most challenging jobs associated with division leadership is identifying and counseling low and middle faculty achievers and applying consistent metrics for remediation or dismissal where appropriate.

8. The key to faculty member retention is continuous stimulation in accordance with the needs, wants, and talents of the individual faculty members.

9. Sex diversity and overall diversity among the faculty are extremely important.

10. Philanthropic pursuits are essential for the maintenance and continued propagation of important programs in any academic cardiothoracic surgical division.

11. A good working knowledge of finances and financial management is necessary to develop budgets, manage day-to-day operations, make intelligent decisions about future expenditures, and communicate and receive information from the institutional administration.

12. A uniform, consistent, transparent plan for reimbursement avoids unrest and dissension among faculty members.

13. The recruitment package for new faculty members constitutes the blueprint for gauging the progress of these individuals during the first 1 to 2 years in their practice and therefore must be very specifically defined.

14. Academic cardiothoracic division chiefs must be prepared to spend significant time and effort on the logistics and execution of residency training, as required by the American Board of Thoracic Surgery, the Thoracic Surgery Residency Review Committee, and the Accreditation Council for Graduate Medical Education.

15. The landscape of cardiothoracic surgery residency is changing. Programs and program directors must maintain a very open mind and be nimble with regard to their approaches to the nature and timing of residency training, operative skills assessments, and simulation.

16. For cardiothoracic surgery residency training, the 2 most important final metrics are successful passing of the American Board of Thoracic Surgery examinations and the successful development of a career as an independent surgeon. The preparation of our residents for these endeavors is perhaps the most important thing that we as academic cardiothoracic surgeons do, and anyone in academic cardiothoracic surgery must have the teaching and development of new young surgeons as a high priority.

From a personal perspective, the AATS Academy came at a very good time in my career and provided me with essential information that has served me well in my early transition as division chief.

The personal experience of our other attendee (V.S.R.) was also very positive: The range of topics was broadly applicable to those currently in leadership, as well as those who are emerging into leadership roles. For example, the portion of the curriculum dedicated to division finances and compensation was very useful to surgeons looking at potential division chief jobs, as well as those currently in those positions looking for other models. Another major benefit of the Academy was the opportunity to develop contacts and relationships within the specialty that might not have otherwise occurred. In particular, opportunities for mentorship, for cross-collaboration, and for resource sharing could all be potential outgrowths from the common experience.

Whereas most corporations offer internal management training seminars, and although health care management degrees do exist, there are no specialty-specific programs such as this that have been documented in the literature. The AATS Academy is solely focused on the development of thoracic surgeons as educational, financial, managerial, and institutional leaders within their respective organizations. Those of us who attended (V.S.R., J.S.I) certainly emerged both with an improved managerial tool kit and with contacts and resources to call on for real life challenges that may develop. 